\title{
APLIKASI CRM JASA SERVIS AIR CONDITIONER PADA JAYA SERVICE BERBASIS ANDROID
}

\section{Samuel Van Basten Manurung ${ }^{\bowtie}$, Indra M. Sarkis Simamora, Rio Aprijal Manurung, Asaziduhu Gea}

Teknik Informatika, Universitas Methodist Indonesia, Medan, Indonesia Email: samuelvanbastenmanurung070189@gmail.com

DOI: https://doi.org/10.46880/jmika.Vol5No1.pp17-22

\begin{abstract}
In the current era, many Android applications have been used in the process of requesting goods or services that can facilitate activities, especially placing orders, especially in the case study below using services made by the company $C V$. Jaya Service, this service is difficult to promote by $C V$. Jaya Service because it only posts small banners on the side of the road so that the income level of this ac service does not increase or even decrease. In addition, the current process, customers always order ac service directly to the location, this takes a long time, and in the sales inspection process it becomes difficult and takes a long time. Customer relation management is needed to maximize activities or Many marketing items, sales, and sales processes are currently done automatically. Analytical customer relation management is very useful in exploiting data from customers in order to increase the quality value of the company, through a CRM business strategy that will be combined with a process, humans, with technology. assist in the process of adding customers related to sales, converting the company to permanent members, and maintaining existing permanent members, satisfied and loyal permanent members. This study aims to design a CRM Service AC Service on Android-based Jaya Service. From the results of this study, the system built can make it easier for customers to order ac service easily directly via cellphones and can provide convenience to Jaya Service in seeing incoming orders and the results of service order transactions.
\end{abstract}

Keyword: CRM, Application, Ordering, AC Service, Customer.

\begin{abstract}
ABSTRAK
Di era sekarang sudah banyak menggunakan aplikasi android di dalam proses permintaan barang atau jasa yang dapat mempermudah kegiatan terutama melakukan pemesanan, terutama di dalam studi kasus di bawah ini menggunakan jasa yang dibuat oleh perusahaan CV. Jaya Service, Jasa Sevice ini sulit untuk di promosikan oleh CV. Jaya Service karena hanya menempelkan spanduk-spanduk kecil di pinggir jalan sehingga tingkat pendapatan dari service ac ini ini tidak mengalami penaikan atau bahkan penurunan . Selain itu, Proses yang sedang berjaan saat ini, pelanggan selalu memesan jasa service ac ini secara langsung ke lokasi, hal ini memakan waktu yang lama, serta dalam proses pemeriksaan penjualan menjadi sulit dan pelayanan yang lama.Customer relation management sangat dibutuhkan untuk memaksimalkan kegiata ataupun item - item pemasaran, penjualan, serta proses penjualan saat ini banyak yang dilakukan secara otomatis.Customer relation management secara analitis sangat bermanfaat di dalam mengeksploitasikan data dari customer agar terjadi peningkatan nilai mutu dari perusahaan, melalui CRM strategi bisnis yang akan dikombinasikan dengan sebuah proses, manusia, dengan teknologi.membantu di dalam proses penambahan cutomer yang berkaitan dengan penjualan, mengkonversi perusahaan menjadi anggota tetap , dan mempertahankan anggota tetap yang ada, anggota tetap yang puas dan loyal. penelitian ini bertujuan unutk merancang CRM Jasa Service AC pada Jaya Service Berbasis Android. Dari hasil penelitian ini, sistem yang dibangun dapat memudahkan pelanggan memesan jasa service ac dengan mudah langsung melalui hp serta dapat dapat memberikan kemudahan kepada Jaya Service dalam melihat pesanan masuk dan hasil transaksi pemesanan jasa.
\end{abstract}

Kata Kunci: CRM, Aplikasi, Pemesanan, Service AC, Pelanggan.

\section{PENDAHULUAN}

Banyak perusahaan yang telah menerapkan sistem pemesanan berbasis android diperusahaannya guna mendukung kinerja perusahaan tetapi tidak sedikit pula yang belum menerapkan sistem pemesanan diperusahaannya sebagai contoh perusahaan CV. Jaya 
Service yang terletak di Jl. Jenderal Besar A.H. Nasution, Pangkalan Masyhur, Kec. Medan Johor, Kota Medan. CV. Jaya Service kesulitan dalam melayani pelanggan sesuai permintaan dikarenakan pencatatan yang dilakukan masih manual sehingga terkadang adanya catatan pesanan pelanggan yang hilang dikarenakan human eror dan faktor lainnya. Banyaknya pelanggan yang datang ke CV. Jaya Service pada saat yang bersamaan juga menjadi masalah karena sulit dikendalikan dan pesanan pelanggan dapat tertukar satu dengan yang lainnya sehingga tidak dapat di layani sesuai permintaan. Oleh Sebab itu diperlukan aplikasi agar pelanggan dapat memesan jasa service AC langsung melalui aplikasi dan pesanan dapat di layani dengan baik.

Dalam perkembangan IT sekarang yang mulai meningkat perlu dibuat sebuah aplikasi yang berbasis online yang di dalamnya melakukan kegiatan atau permintaan jasa dan barang lebih mudah dan diantar ke tempat atau istilahnya sekarang COD. adapun dengan perkembangan tersebut mmerupakan salah satu bentuk services yang sangat memuaskan dengan menggunakan Customer Relationship Management (CRM). CV. Jaya Service ingin mengadakan promosi seperti "5 kali service gratis 1 kali service" dapat dengan mudah sampai kepada kepada konsumen sekaligus menarik konsumen dengan CRM teknik bisnis dengan cara kombinasi proses yang ada, human, dan IT. membantu di dalam proses promosi penjualan, mengkonversi customer menjadi anggota tetap, dan menjadi anggota yang tetap di dalam perusahaan, dan membuat anggota tetap memiliki loyalitas yang penuh.

\section{TINJAUAN PUSTAKA}

\section{Customer Relationship Management (CRM)}

Pada penelitian ini CRM merupakan suatu cara yang dilakukan di dalam suatu organisasi agar dapat sesuai dengan tujuan atau gol yang dicapai dengan menggunakan IT dalam bentuk CRM unutk bisnis, akan tetapi disesuaikan dengan jenis bisnis dan sejauh mana bisa digunakan customer relation management untuk memanage permasalahan yang telah diketahui ketika sebelum dan sesudah pelaksanaan Customer relation management tersebut (Rahmawati, Kusniawati, \& Setiawan, 2019). Akan tetapi tidak semua organisasi yang melaksanakan CRM itu berhasil. Untuk memperoleh implementasi CRM yang berhasil organisasi-organisasi hendaknya mengevaluasi CRM tersebut sesuai dengan seluruh strategi bisnis mereka seutuhnya, mengevaluasi kapasitas-kapasitas CRM nya dan mempunyai alasan bisnis untuk menerapkan CRM. Proses ini hendaknya tidak bisa diacuhkan jika dimanfaatkan sebagaimana dirancangkan, meningkatkan nilai yang dirasakan pelanggan sehingga akan menaikan tingkat kepuasan mereka sampai ke titik dimana pelanggan itu setia kepada perusahaan (Rahayu, Faiza Renaldi, \& Umbara, 2018). pada Customer Relation Management memiliki 4 buah dimensi yaitu identifikasi pelanggan (customer identification), membangun daya tarik terhadap pelanggan (customer attraction), mempertahankan pelanggan yang ada (customer retention), dan pengembangan pelanggan (customer development) (Simarmata \& Hasibuan, 2018).

\section{Aplikasi}

Pada penelitian ini, aplikasi merupakan suatu program yang secara langsung yang dimanfaatkan untuk mempermudah di dalam proses pembuatan sistem di dalam melakukan kegiatan yang diminta oleh user. adapun aplikasi tersebut bisa berbasis destop dan online (Tamansa, Pontoh, \& Tompodung, 2018).

Aplikasi merupakan sejumlah source code yang bisa dirancang agar bisa/ dapat mempermudah di dalam proses keguatan yang diinginkan oleh user (Setiadi, Yuliatmojo, \& Nurhidayat, 2018).

Aplikasi bisa dibilang software yang dipakai sesuai dengan kebutuhan yaitu proses pengoperasian dokumen, mengatur tampilan layar, game, pembuatan website, daln lain-lain sesuai dengan kebutuhan user (Aprianto, Wulandari, \& Hafifah, 2018).

\section{Sistem Informasi}

Kombinasi dari teknologi informasi dan aktivitas orang yang menggunakan teknologi itu untuk mendukung operasi dan manajemen. Dalam arti yang sangat luas, istilah sistem informasi yang sering digunakan merujuk kepada interaksi antara orang, proses algoritmik, data, dan teknologi. Dalam pengertian ini, istilah ini digunakan untuk merujuk tidak hanya pada penggunaan organisasi teknologi informasi dan komunikasi (TIK), tetapi juga untuk cara di mana orang berinteraksi dengan teknologi ini dalam mendukung proses bisnis merupakan pengertia dari sistem informasi (Hutriana \& Fitrian, 2017; Nurmayanti, 2018).

\section{METODE PENELITIAN}

\section{Analisa Kebutuhan}

Sistem yang berjalan saat ini adalah masih dengan pemesanan secara manual dan pelanggan harus datang langsung ke lokasi untuk memesan jasa service AC. Jasa Sevice ini sulit untuk di promosikan oleh CV. 
Jaya Service karena hanya menempelkan spandukspanduk kecil di pinggir jalan sehingga tingkat pendapatan dari service ac ini ini tidak mengalami penaikan atau bahkan penurunan, oleh sebab itu dirancang aplikasi pemesanan jasa service AC agar dapat memudahkan pelanggan pada saat memesan jasa service AC tanpa datang langsung datang ke lokasi dan dapat direspon oleh CV. Jaya Service dengan cepat serta lebih efisien. Selain itu CV. Jaya Service juga dapat membuat promo di aplikasi agar dapat dilihat langsung oleh pelanggan serta menarik minat pelanggan.

\section{Analisis Fungsional}

Analisis fungsional merupakan bagian yang menunjukkan bahwa manfaat dari aplikasi yang telah dibuat. Adapun manfaat dari aplikasi tersebut adalah Activity Diagram Admin dan Activity Diagram User.

\section{Activity Diagram Admin}

Di dalam Activity ini menjelaskan apa saja tugas dari seorang admin dalam aplikasi. Admin terlebih dahulu harus login untuk masuk ke halaman akun admin. Setelah login admin dapat melakukan tugas seperti mengolah data admin, mengolah data pesanan, mengolah data jasa,mengolah hasil pembayaran dan logout dari sistem. Gambar Activity ini dapat dilihat pada gambar 1 .

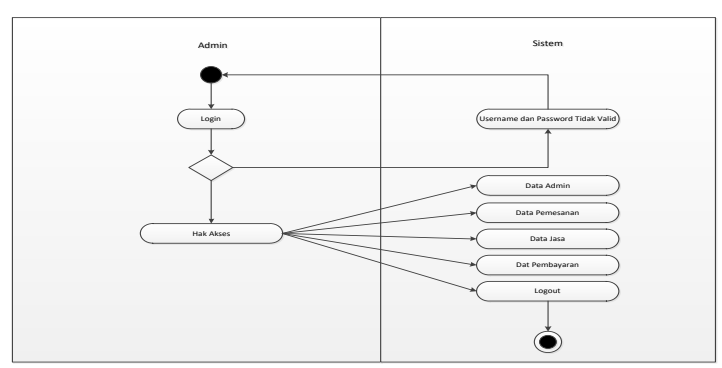

Gambar 1. Activity Diagram Admin

\section{Activity Diagram User}

Activity ini menjelaskan apa saja tugas dari seorang pengguna dalam android. Pengguna terlebih dahulu harus login untuk masuk ke halaman akun pengguna. Setelah login pengguna dapat melakukan tugas seperti ,mengolah data pengguna, membuat laporan, melihat undang-undang perlindungan anak dan logout dari android. Activity Diagram akun pengguna di android dapat dilihat pada gambar 2 .

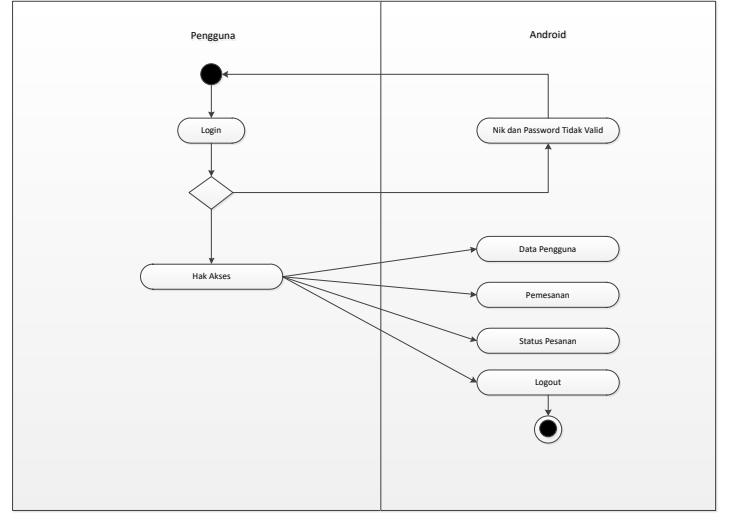

Gambar 2. Activity Diagram User

\section{HASIL DAN PEMBAHASAN}

\section{Tampilan SplashScreen}

Tampilan splashscreen adalah tampilan awal sewaktu pertama kali membuka aplikasi. Tampilannya dapat dilihat pada gambar 3:

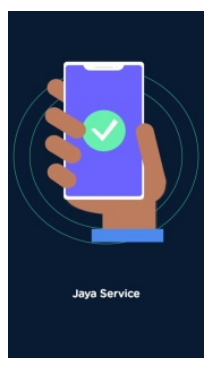

Gambar 3. Tampilan Splashscreen

\section{Tampilan Sampul}

Tampilan sampul adalah tampilan ini akan muncul setelah splashscreen, adapun tampilan tersebut adalah login dan register. Tampilan sampul dapat dilihat pada Gambar 4:

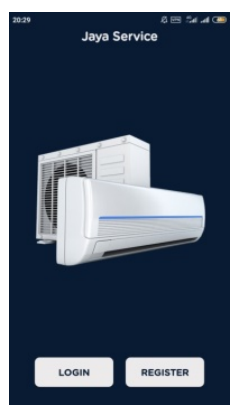

Gambar 4. Tampilan Sampul

\section{Tampilan Login}

Tampilan login berfungsi bagi untuk input data user dan password sebelum masuk ke halaman akun. Tampilan login dapat dilihat pada gambar 5: 


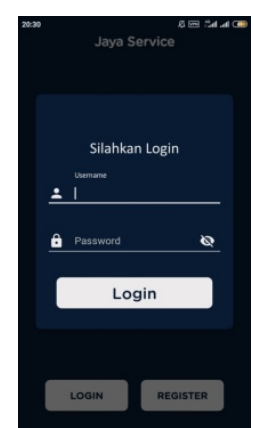

Gambar 5 Tampilan Login

\section{Tampilan Register}

Form register ini berfungsi untuk mendaftarkan user baru pada aplikasi. Tampilan register dapa dilihat pada gambar 6:

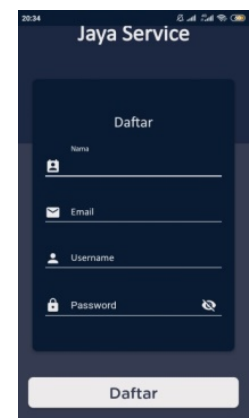

Gambar 6. Tampilan Register

\section{Tampilan Menu}

Tampilan Menu, pada form ini user dapat memilih menu yang diinginkan untuk melakukan pemesanan service. Tampilan pengaturan akun user dilihat pada gambar 7 :

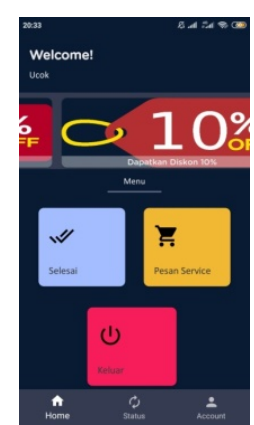

Gambar 7. Tampilan Pemesanan

\section{Tampilan Buat Pesanan}

Tampilan berfungsi untuk membuat pesanan yang dilakukan oleh user untuk memesan jasa service AC. Tampilan dapat dilihat pada gambar 8 :

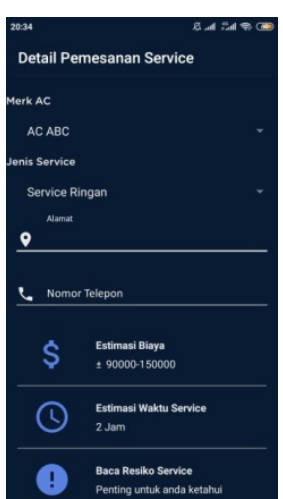

Gambar 8. Tampilan Buat Pesanan

\section{Tampilan Status Pesanan}

Tampilan menampilkan status pesanan yang sedang dikerjakan. Tampilan dapat dilihat pada gambar 9 berikut:

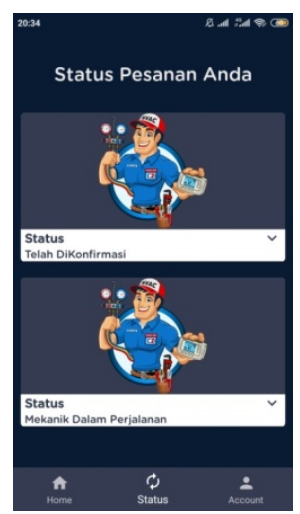

Gambar 9. Tampilan Status Pesanan

\section{Tampilan Pengaturan Akun}

Tampilan pengaturan akun user, pada form ini user dapat mengupdate info akun mereka seperti nama,email dan password. Tampilan pengaturan akun dapat dilihat pada Gambar 10:

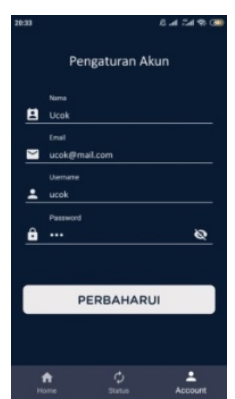

Gambar 10. Tampilan Pengaturan Akun

\section{Tampilan Menu Admin}

Tampilan Menu admin berfungsi admin memilih fitur yang ada pada menu serperti pesanan masuk,pesanan selesai,promosi dan main menu. Tampilan dapat dilihat pada Gambar 11: 


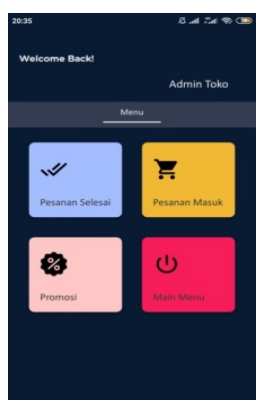

Gambar 11. Tampilan Pengaturan Akun

\section{Tampilan Pesanan Masuk}

Tampilan ini menampilkan pesanan yang masuk pada toko service untuk dikerjakan. Tampilan pesanan masuk dapat dilihat pada gambar 12:

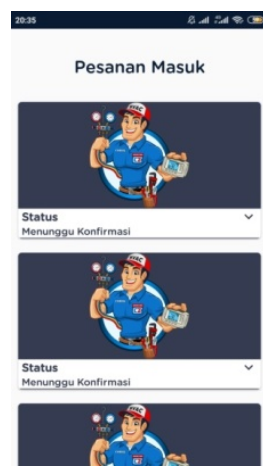

Gambar 12. Tampilan Pesanan Masuk

\section{Tampilan Edit Promosi}

Tampilan ini berguna untuk mengolah data informasi edit promosi. Tampilan dapat dilihat pada Gambar 13:

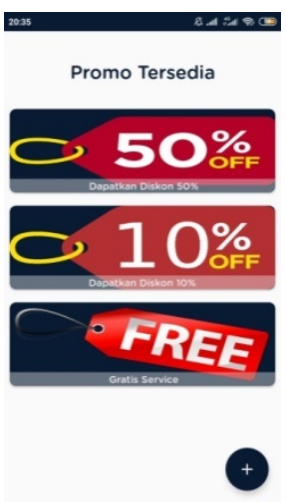

Gambar 13. Tampilan Edit Promosi

\section{Tampilan Tambah Promosi}

Tampilan ini berguna untuk mengolah data informasi tambah promosi.Tampilan dapat dilihat pada Gambar 14:

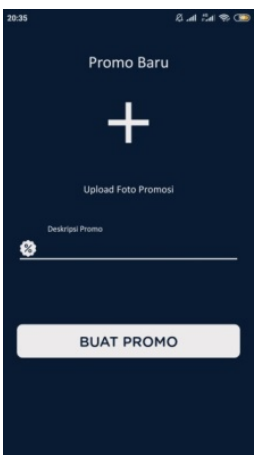

Gambar 14. Tampilan Tambah Promosi

\section{KESIMPULAN}

Kesimpulan dari penelitian yang telah dilakukan bahwa sistem yang dibangun memudahkan pelanggan di dalam proses pemesanan jasa service ac dengan cepat menggunakan handphone agar dapat mempermudah CV. Jaya Service dalam melihat proses pesanan masuk dan hasil transaksi pemesanan jasa serta membantu di dalam peningkatan loyalitas pelanggan terhadap perusahaan dengan menaikkan offset jangka panjang.

\section{DAFTAR PUSTAKA}

Aprianto, R., Wulandari, \& Hafifah, N. (2018). Pengembangan Aplikasi Web Mobile Penjadwalan Tugas Aparatur Desa Untuk Meningkatkan Layanan Masyarakat. Jurnal Teknologi Komputer Dan Sistem Informasi, 1(3), 81-86.

Hutriana, L., \& Fitrian, Y. (2017). SISTEM PENDUKUNG KEPUTUSAN PEMILIHAN HANDPHONE. Prosiding Konferensi Mahasiswa Sistem Informasi, 309-314. STMIK Pringsewu.

Nurmayanti. (2018). SISTEM INFORMASI SEKOLAH BERBASIS WEB PADA SMK KARYA DHARMA 1 ABUNG SELATAN PROVINSI LAMPUNG UTARA. Jurnal Informasi Dan Komputer, 6(1), 10-19.

Rahayu, G., Faiza Renaldi, \& Umbara, F. R. (2018). Pembangunan Customer Relationship Management (CRM) pada PT. Sanbe Farma. Prosiding Seminar Nasional Sains Dan Teknologi, 208-213. Universitas Wahid Hasyim Semarang.

Rahmawati, Y. O., Kusniawati, A., \& Setiawan, I. (2019). Pengaruh Customer Relationship Management dan Kualitas Pelayanan Terhadap Loyalitas Konsumen Sepeda Motor Yamaha (Studi Pada Konsumen Bahana Ciamis). Business Management and Entrepreneurship Journal, 1(4), 102-115.

Setiadi, A., Yuliatmojo, P., \& Nurhidayat, D. (2018). 
PENGEMBANGAN APLIKASI ANDROID

UNTUK PEMBELAJARAN PNEUMATIK.

JURNAL PENDIDIKAN VOKASIONAL

TEKNIK ELEKTRONIKA (JVOTE), 1(1), 1-5.

https://doi.org/10.21009/jvote.v1i1.6886

Simarmata, E. R., \& Hasibuan, D. (2018).

Implementasi Customer Relationship

Management (CRM) Pada Aplikasi Penjualan

Berbasis Web PT. Buana Telekomindo. Jurnal

TIMES, 7(1), 8-14.

Tamansa, V. L., Pontoh, F. J., \& Tompodung, M. L.

(2018). PERANCANGAN APLIKASI

PENGATURAN KEUANGAN PRIBADI

BERBASIS ANDROID. E-Jurnal UNSRIT,

5(2), 55-60. 